\title{
Smart Wheelchair: A Literature Review
}

\author{
Kedar Sukerkar*, Darshitkumar Suratwala, Anil Saravade, Jairaj Patil, Rovina D'britto
}

Department of Information Technology, Atharva College of Engineering, India

\begin{tabular}{l} 
Article Info \\
\hline Article history: \\
Received Apr 7, 2018 \\
Revised Jun 14, 2018 \\
Accepted Jun 28, 2018 \\
\hline
\end{tabular}

Keyword:

Artificial intelligence

Robotics

Sensors

Smart wheelchair

\begin{abstract}
In today's world there are many disabled persons who find it difficult to perform movements or perform daily activities. This types of persons are mainly dependent on others for their assistance. But they can become selfindependent and perform some daily activities on their own with the help of assistive devices. The most widely used assistive devices are Wheelchairs. Wheelchairs is basically a chair fitted with wheels, which can help people move around who cannot walk because of illness, disability or injury. But there are many disabled people with weak limbs and joints who cannot move the wheelchair. Thus, smart wheelchair can benefit a lot to them and everyone in society. Smart wheelchairs are electric powered wheelchairs with many extra components such as a computer and sensors which help the user or guardian accompanying wheelchair to handle it easily and efficiently. The recent development in the field of Artificial Intelligence, sensor technologies and robotics help the growth of wheelchairs with new features. This paper is to review the current state of art of smart wheelchairs and discuss the future research in this field.
\end{abstract}

Copyright () 2018 Institute of Advanced Engineering and Science. All rights reserved.

\section{Corresponding Author:}

Kedar Sukerkar, Department of Information Technology, Atharva College of Engineering, India. Email: project.awc@gmail.com

\section{INTRODUCTION}

Any condition of body or mind that makes it more difficult for the person with the condition to do certain activities and interact with the world around them is termed as disability. Census conducted in 2001 has revealed that around 21 million people from India i.e. $2.1 \%$ of total country's population are suffering from disability of some kind or another. In 2011, census reported that there has slight increase from $2.1 \%$ to $2.21 \%$. Out of which people suffering from disability of movement is large [6]. Disability of movement is deformity of body due to which person suffering finds difficult to move from one place to another and perform daily activities. Disability of movements can occur by birth or due to accidents or various other reasons. So, use of assistive devices can prove to be of great help to such peoples. Assistive device are any devices which help to overcome people suffering from disabilities. Most commonly used assistive devices are wheelchairs. Wheelchair is nothing but a chair fitted with four wheels and can be easily moved from one place to another. Manual/traditional wheelchair require physical force by the user, which cannot be considered as the efficient way because, it may cause discomfort for the user with weak limbs and bones. This is why, electric powered wheelchair are generally preferred over traditional and manual wheelchair. Electric powered wheelchair are easy to use and require minimal force to control the wheelchair.

Electric and traditional wheelchair often solve the problem of mobility for disabled persons. But, there are certain segment of disabled person who suffer from low vision, visual field reduction, spasticity, tremors, cognitive deficits, etc. These people largely rely on other people for controlling the wheelchair. Controlling wheelchair all by themselves is not safe. To solve this problem, researchers have come up with the discovery of "Smart Wheelchair". 
Smart wheelchair are nothing but an electric powered wheelchair which also consists of a computer and various sensors. Smart wheelchair provides great safety of the user and are easy to use. Table 2.

This paper consists of current state of art and discussion about future research. Shown in Table 1 and

Table 1. Percentage of Disabled to Total Population India, 2011

\begin{tabular}{lllll}
\hline Sr. No. & Residence & Male & Female & Persons \\
\hline 1 & Rural & 2.43 & 2.03 & 2.24 \\
2 & Urban & 2.34 & 1.98 & 2.17 \\
Total & & 2.41 & 2.01 & 2.21 \\
\hline
\end{tabular}

Table 2. Proportion of Disabled Population by Type of Disability India, 2011

\begin{tabular}{lllll}
\hline Sr. No. & Types of Disabilities & Male & Female & Total \\
\hline 1 & In Seeing & 17.6 & 20.2 & 18.8 \\
2 & In Hearing & 17.9 & 20.2 & 18.9 \\
3 & In Speech & 7.5 & 7.4 & 7.5 \\
4 & In Movement & 22.5 & 17.5 & 20.3 \\
5 & Mental Retardation & 5.8 & 5.4 & 5.6 \\
6 & Mental Illness & 2.8 & 2.6 & 2.7 \\
7 & Any Other & 18.2 & 18.6 & 18.4 \\
8 & Multiple Disability & 7.8 & 8.1 & 7.9 \\
Total & & 100.00 & 100.00 & 100.00 \\
\hline
\end{tabular}

\section{SMART WHEELCHAIR}

In recent years, smart wheelchair have been greatly considered over power wheelchair. Power wheelchair are traditional/manual wheelchair with battery or electric supply to power them. They largely lack functionalities and safety features. Unlike this, smart wheelchair have functionalities and safety features.

Smart wheelchair consists normally of electric powered wheelchair with a computer and many sensors. Continuous development in field of artificial intelligence, computing and robotics have led to growth in Smart wheelchair. Smart wheelchair consists of computer, which is responsible for the movements of the wheelchairs with help of inputs from the sensors. Sensors collects the data through the input from environment and that data is processed by computer and necessary steps are taken. Smart wheelchair can be also controlled manually by the user just like normal electric powered wheelchair.

\section{CLASSIFICATION FACTORS OF SMART WHEELCHAIR}

\section{A. Form Factor}

Smart wheelchair can be classified based on certain factors as follows.

Some early smart wheelchairs developed were actual mini-robots that were attached to seats. These wheelchairs are expensive compared to other wheelchairs. For example Véhicule Autonome pour Handicapé Moteur [VAHM] [1], Mister Ed [2].

Other smart wheelchairs which are commercially popular are "add-on" units which can be purchased separately and can be easily attached to normal power wheelchairs. They are preferred because they are compatible with many electric power wheelchairs. The typical use of this "add-on" units are suitable for Kids because they go through many different sizes of wheelchair due to their body growth. Some examples Smart Wheelchair Component System [SWCS] [10], Smart Power Assistance Module [SPAM] [11], Hephaestus [12], TinMan [13], Siamo [14].

\section{B. Input Methods}

There can be various input methods for the smart wheelchairs based on user specific preferences. Some input methods for smart wheelchair are biometrics, cloud, touch, voice, computer vision, brain computer interface, haptic feedback, etc. All input methods have their own use and should be selected based on the needs.

C. Sensors

Various sensors such as infrared sensors, ultrasonic sensors, laser range finder, camera's, etc. are used for providing inputs to the smart wheelchair. Sensors provide inputs from the surroundings and inputs in 
processed by the computer of the wheelchair. Sensors are generally used for providing safety features to smart wheelchair.

Ultrasonic sensors use sonar technology and are very good in terms of accuracy. Sonar sensors use sound for obstacle detection. The sound is emitted from the sensors and the sound reflected from the surfaces is used for finding the distance between objects.

Infrared sensors are also used for obstacle and collision detection. Infrared sensors use light instead of sound for distance finding. Both these sensors are cheap and are accurate in normal conditions. These sensors can get wrong input if the floors, stairs, surfaces, etc. are smooth, sound absorbent and light absorbent. However, due to their limitations, they are still used because they are cheap, accurate and their technology is well known.

Laser Range Finder (LRF) are very good alternative to ultrasonic and infrared sensors. They use $180^{\circ}$ two dimensional scan for scanning the environment. Their cost is expensive and are more accurate compared to them.

Cameras are considered to be very accurate. Due to technological advancement in cameras, they are have great accuracy rate in scanning the environment. They are smaller in size and can be easily fitted onto the smart wheelchair.

\section{Operating Modes}

Operating modes of wheelchair is another important distinguishing factor of smart wheelchair. Operating modes of wheelchair depend upon the user ability and according to the current situation. Smart wheelchair system can be autonomous or semi-autonomous. Users who cannot control the wheelchair safely on their own are benefited with autonomous systems. Autonomous systems can travel to desired destination automatically and safely and they require pre-knowledge of the environment. These systems uses machine learning, navigation, localization and mapping techniques. Users which can control the wheelchair and travel to desired destination safely can use semi-autonomous system. These systems contains collision detection and avoidance technique for safety measures. Additional safety measures can also be added depending upon the user.

\section{FUTURE RESEARCH}

Smart wheelchair will be an important necessity in future. Smart wheelchair provide great opportunity for development of sensors and mobile robots technology. Development of these things can reduce the cost factor to a great extent. Hardware and software development are also an important part of smart wheelchair success. Working on reviews and feedbacks can help to improve the current issues of wheelchair system and also new ideas can be imagined.

\section{CONCLUSIONS}

There are several issues faced by the manufacturers and researchers which needs to be addressed so that, smart wheelchair becomes a commercial success and be widely used. One common main issue is cost versus accuracy. Inexpensive and advanced sensors can help to overcome this problem. Smart wheelchairs which can be used generally used for all types of disability are still not available. Smart wheelchairs should also contain the ability to monitor the patient conditions and react accordingly. Currently available smart wheelchairs can be easily used in indoor conditions but, for outdoor environment it requires supervision by a companion for safety. Also, smart wheelchair for independent use by mentally challenged people should be researched. Smart wheelchair have great scope in future and technological advancement in the field of robotics and sensors will lead to commercial success as well.

\section{REFERENCES}

[1] C-Series, Table C-20, Census of India 2001 and 2011.

[2] Bourhis, G., Moumen, K., Pino, P., Rohmer, S., Pruski, A., “Assisted navigation for a powered wheelchair. Systems Engineering in the Service of Humans: Proceedings of the IEEE International Conference on Systems, Man and Cybernetics; 1993 Oct 17-20; Le Touquet, France. Piscataway (NJ): IEEE; 1993. p. 553-58.

[3] Connell, J., Viola, P., "Cooperative control of a semi-autonomous mobile robot". Robotics and Automation: Proceedings of the IEEE International Conference on Robotics and Automation (ICRA); 1990 May 13-18; Cincinnati, OH. Piscataway (NJ): IEEE; 1990. p. 1118-21.S. Zhang, C. Zhu, J. K. O. Sin, and P. K. T. Mok, "A novel ultrathin elevated channel low-temperature poly-Si TFT," IEEE Electron Device Lett., vol. 20, pp. 569-571, Nov. 1999.

[4] Simpson R.C, LoPresti EF, Hayashi S, Nourbakhsh I.R, Miller D.P., "The smart wheelchair component system”. J Rehabil Res Dev. 2004; 41(3B):429-42. 
[5] Simpson, R.C, LoPresti E.F, Hayashi S, Guo S, Ding D, Cooper R.A., "Smart Power Assistance Module for manual wheelchairs". Technology and Disability: Research, Design, Practice and Policy: 26th International Annual Conference on Assistive Technology for People with Disabilities (RESNA) [CD-ROM]; 2003 Jun 19-23; Atlanta, GA. Arlington (VA): RESNA Press; 2003.

[6] Simpson, R.C, Poirot D, Baxter M.F., "The Hephaestus smart wheelchair system". IEEE Trans Neural Syst Rehabil Eng. 2002; 10(2):118-22.

[7] Miller, D.P., Slack, M.G., "Design and testing of a low-cost robotic wheelchair prototype". Auton Robots. 1995; 2(1): 77-88.

[8] Mazo M., “An integral system for assisted mobility”. IEEE Robot Autom Mag. 2001; 8(1):46-56. 